\title{
Postmenopozal Tubo Ovaryan Abse ile Prezente Olan Seröz Over Karsinomu Olgusu
}

\author{
A Case of Serous Ovarian Carcinoma Presenting with Postmenopousal Tubo-Ovarian Abscess
}

\author{
Sezin Ertürk Aksakal ${ }^{1}$, Fusun Bocutoglu ${ }^{1}$, Şadiman Kıykac Altınbaş ${ }^{1}$, Erhan Demirdağ ${ }^{1}$, Ali Rıza Doğan ${ }^{1}$ \\ Betül Zuhal Işıkdoğan ${ }^{2}$, İnci Kahyaoğlu ${ }^{1}$, Ömer Lütfi Tapısız ${ }^{1}$
}

${ }^{1}$ Jinekoloji Kliniği, Etlik Zübeyde Hanım Kadın Hastalıkları Eğitim ve Araştırma Hastanesi, Ankara, Türkiye
${ }^{2}$ Patoloji Kliniği, Etlik Zübeyde Hanım Kadın Hastalıkları Eğitim ve Araştırma Hastanesi, Ankara, Türkiye

ÖZET

Tubaovarian abse (TOA) üreme çağındaki kadınlarda önemli bir sağlık sorunu oluşturmaktadır ve postmenopozal hastalarda nadiren gözükmektedir. Üreme çağında PID (Pelvik Inflamatuar Hastalık) nedeniyle hospitalize edilen hastaların \%34'ünde TOA gelişmektedir. Postmenopozal hastalarda, eşlik eden jinekolojik malignensi olabileceği göz önünde bulundurulmalıdır. Bu olgu sunumunda TOA kliniği ile prezente olan ovarian malignensi olgusunu sunmayı amaçladık. Altmışüç yaşında hasta, 3 aydır devam eden kasık ağrısı şikayeti ile kliniğimize başvurdu. Hastanın öyküsünden, 18 yıldır menapozda olduğu, geçirilmiş cerrahisinin bulunmadığı, hipertansiyon dışında sistemik hastalığı ve antihipertansif dışında devamlı kullandığı ilacı olmadığı öğrenildi. Pelvik muayenede sağ adneksial dolgunluk dışında özellik yoktu. Yapılan transvajinal ultrasonografide kavitede $21 \times 39 \mathrm{~mm}$ sıvı kolleksiyonu ve sağ adnekste $36 \times 36$ $\mathrm{mm}$ internal eko içeren kistik oluşum, TOA? izlenmesi üzerine, hastaya genel anestezi altında endoservikal küretaj ve probe küretaj yapıldı. Endometrial örnekleme sonucunda; takibe uygun materyal izlenmedi şeklinde raporlandı. Transvajinal ultrasonografi (USG) ile kavitede sIVı kolleksiyonunun sebat etmesi üzerine hastaya gentamisin ve klindamisin antibiyoterapisi başlanarak teedavinin 3. gününde laparaskopik abse drenajı ve abse duvarı örneklemesi yapıldı. Patoloji sonucu malign epitelyal tümör olarak raporlandı, abse kültüründe üreme olmadı. Bir hafta sonra hastaya evreleyici cerrahi yapıldı. Postoperatif patoloji sonucu FIGO (International Federation of Gynecology and Obstetrics) evre IIIC tümör olarak raporlandı. Hasta 6 kür paklitakselkarboplatin kemoterapisi verildi. Postmenapozal tubo ovaryan abse ile prezente olan hastalar, eşlik eden pelvik malignensiler açısından detaylı araştııımalı ve sadece medikal ya da konservatif tedaviden kaçınıımalıdır.

Anahtar Sözcükler: TOA, seröz karsinom

Geliş Tarihi: 06.03.2017

Kabul Tarihi:03.06.2017
Received: 03.06 .2017

Accepted:06.03.2017

\begin{abstract}
Tuboovarian abscesses (TOAs) are considered to be a problem during a woman's reproductive ages, and the diagnosis appears to be infrequent in postmenopausal women. It has been reported that $34 \%$ of patients hospitalized with a diagnosis of acute genital tract infections in reproductive ages develop TOA. It seems to be a serious problem to be solved that TOA may be related to a concomitant gynecological malignancy in a postmenopausal woman. In this case report we aimed to present a case of serous ovarian carcinoma presenting with postmenopousal tubo-ovarian abscess. A-63 year old postmenopausal patient was admitted to our gynecological outpatient clinic with a history of 3 months ongoing lower abdominal pain. The patient has been in menopause for 18 years. Her medical history was unremarkable with no previous surgery and systemic disease, except hypertension. Her initial gynecological pelvic examination presented right adnexal fullness. A transvaginal ultrasound scan revealed fluid collection of $39 \times 21 \mathrm{~mm}$ in the uterine cavity and a $3.5 \mathrm{~cm}$ right adnexal cystic formation suspicious for TOA without any other pathology of the genitourinary system. Endocervical curettage and probe curettage were performed under general anesthesia. Unfortunately, pathological findings did not provide enough material for diagnosis. Because of the persistence of fluid collection and an adnexal mass, the patient was hospitalized and an antibiotic regimen of gentamicin and clindamycin intravenously was started. On the third day of antibiotic therapy, exploratory laparoscopic operation was planned and drainage and abscess wall sampling was performed. The pathological result revealed malign epithelial tumor and no microorganism was defined on abscess culture. Because of pathological result, tumoral debulking and staging surgery was performed. The patient was diagnosed as having a FIGO (International Federation of Gynecology and Obstetrics) stage IIIC tumor, and received six cycles of paclitaxel and carboplatin regimen after surgery. Patients presenting with postmenopausal TOA should be investigated in detail to exclude a concomitant gynecological or any other pelvic malignancy. In order to obviate any delay in the diagnosis and treatment, medical treatment alone or conservative treatment should be avoided.
\end{abstract}

Key Words: Tubo-ovarian abscess, ovarian carcinoma

\section{GiRiş}

Pelvik inflamatuvar hastalık (PID) endometrit, salpenjit, tubaovaryan abse, pelvik peritonit ve bunların değişen kombinasyonları dahil olmak üzere, kadın üst genital traktusunun inflamatuvar hastalıklarını içeren bir spektrumdur. trachomatis çoğu vakadan sorumludur (1). PiD, sıklıkla reprodüktif dönemdeki kadınlarda izlenmektedir. Postmenapozal kadınlarda nadir görülmekle birlikte insidansı bilinmemektedir (2).

Bu olgu sunumunun özeti, 11. Türk Alman Jinekoloji (TAJEV) Kongresinde poster olarak sunulmuştur.

Yazışma Adresi / Address for Correspondence: Dr. Sezin Ertürk Aksakal, Etlik Zübeyde Hanım Kadın Hastalıkları Eğitim ve Araştırma Hastanesi, Jinekoloji Kliniği, Ankara, Türkiye E-posta: drsezert@gmail.com

(C)Telif Hakkı 2017 Gazi Üniversitesi Tıp Fakültesi - Makale metnine http://medicaljournal.gazi.edu.tr/ web adresinden ulaşılabilir.

(C) Copyright 2017 by Gazi University Medical Faculty - Available on-line at web site http://medicaljournal.gazi.edu.tr/

doi:http://dx.doi.org/10.12996/gmj.2017.68 
Üreme çağında PID nedeniyle hospitalize edilen hastaların \%34'ünde Tubaovarian abse (TOA) gelişmektedir (3). Bu hastaların güncel tedavisinde uygun antibiyotik tedavisi ile beraber cerrahi drenaj veya enfekte dokuların çıkarılması sıklıkla uygulanmaktadır (4). TOA, postmenapozal hastalarda oldukça nadir görülmekle birlikte, eşlik eden jinekolojik malignensi oranı \%47 olarak bildirilmiştir (5). Bu yazıda postmenopozal dönemde tubaovaryan abselerin yaklaşık yarısında malignite olabileceği ve tedavinin bu yönde planlanmasının önemi belirtilmiştir.

\section{OLGU SUNUMU}

Yaklaşık 13 yıldır menopozda olan 63 yaşındaki hasta, 3 aydır devam eden kasık ağrısı şikâyeti ile hastanemiz jinekoloji polikliniğine başvurdu. Hastanın 18 yıldır menopozda olduğu, geçirilmiş cerrahisinin bulunmadığı, hipertansiyon dışında sistemik hastalığı ve antihipertansif dışında devamlı kullandığı ilacı bulunmadığı öğrenildi. Bimanuel pelvik muayenesinde unilateral adneksiyal dolgunluk tespit edilen hastanın transvajinal ultrasonografisinde kavitede $21 \times 39 \mathrm{~mm}$ sıvı koleksiyonu ile sağ adneksiyal alanda $36 \times 36 \mathrm{~mm}$ TOA ile uyumlu görünüm izlendi. Laboratuvar incelenmesinde beyaz küre $8,841 / \mathrm{mm}^{3}, \mathrm{C}$ reaktif protein (CRP) $1,1 \mathrm{IU} / \mathrm{ml}$ ve tümör belirteçleri normal sınırlarda tespit edilmesi üzerine, hastaya genel anestezi altında endoservikal küretaj ve probe küretaj yapıldı. Oral doksisiklin 500 mg 12 saatte bir, 1 hafta süreyle alması planlanarak patoloji sonucu için çağırıldı. Endometrial örnekleme sonucunda takibe uygun materyal izlenmemesi ve uterin kavitede sıvı koleksiyonunun ve ultrasonografide kitlenin sebat etmesi üzerine hasta hospitalize edilerek intravenöz gentamisin $2 \mathrm{mg} / \mathrm{kg}$ yükleme dozu takiben, 1,5 mg/kg gentamisin ve $900 \mathrm{mg}$ klindamisin 8 saatte bir olacak şekilde alması planlandı. Yatış sırasında hastanın laboratuvar değerleri beyaz küre $8841 / \mathrm{mm}^{3}$, CRP: $6,53 \mathrm{IU} / \mathrm{ml}$, sedimentasyon hızı: 44/93mm, CA125: 4,8 U/ml, CA19-9:10,59 U/ml idi. Hastanın postmenopozal olması, mevcut adneksiyel kitle persistansı sebepleriyle antibiyotik tedavisinin 3. gününde laparoskopik girişim ile kitle eksizyonu planlandı. Operasyonda fossa ovarica'ya adheze, unilateral ovaryan abse oluşumu dışında ek patoloji tespit edilmedi. Patoloji sonucunun malign epitelyal tümör olarak raporlanması üzerine hastanın operasyonu total abdominal histerektomi, bilateral salpingooforektomi, bilateral pelvik ve paraaortik lenf nodu diseksiyonu, total omentektomi, apendektomi olacak şekilde tamamlandı. Postoperatif patoloji sonucu yüksek gradeli seröz karsinom olarak raporlanan ve FIGO (International Federation of Gynecology and Obstetrics) evre IIIC olarak değerlendirilen hastaya 6 kür paklitaksel karboplatin kemoterapisi verildi. Hastanın takiplerine halen devam edilmektedir.

\section{TARTIŞMA}

Adneksiyal kitleler fetus ve postmenopozal hastalar da dahil olmak üzere her yaşta görülebilmektedir. Adneksiyal kitleli postmenopozal kadınlar malignite açısından artmış riske sahiptir. Alcazar ve ark.'nın yaptıkları çalışmada asemptomatik postmenopozal adneksiyal kitlesi olan 91 hastanın \%2'sinde malignite saptanmıştır (6). Bir başka çalışmada ise postmenopozal ovarian kitlesi olan kadınların en az \%30'unda malignite görüldüğü bildirilmiştir (7). Bu yüzden adneksiyal kitlenin tanısında önemli olan malign ya da benign ayrımının yapılmasıdır. Postmenopozal adneksiyal kitlesi olan hastalarda, $5 \mathrm{~cm}$ den büyük, solid komponent içeren, septalı, doppler sonografide düşük akım varlığı, sebat eden kitle ve asit gibi malignite lehine bulgular varlığında cerrahi tedavi ilk seçenek olmalıdır (8). Postmenopozal adneksiyal kitlesi olan hastalar, yüksek CA125 seviyesi, asit, nodüler/fikse kitle ve metastaz varlığında jinekolog onkoloğa refere edilmelidir (8). Kliniğimizin 1 yıllık adneksiyal kitle olgu serisinde toplam 153 hasta adneksiyal kitle nedeniyle opere edilmiştir. 137 hastaya laparoskopik, 16 hastaya laparotomik girişim yapılmıştır. Hastaların 54 tanesi (\%35.2) postmenopozaldir. Postmenopozal adenksiyal kitle tanısıyla opere edilen hastaların 3 tanesinde (\%5.5) malignite saptanmıştır. Bir yıllık süreçte aldığımız vakalar benign patoloji öngörülerek opere edilmiş, buna karşılık postmenopozal adneksiyal kitlelerde \%5.8'lik malignite oranı saptanmış olup malignite düşünülen ya da öngörülen hastalar rutinde jinekolojik onkoloji kliniğinde opere edilmektedir. Bu yüzden tüm adneksiyel kitleler göz önüne alındığında bu oranın daha yüksek olacağını öngörmekteyiz.
Bizim olgumuzda hastanın postmenopozal olması, endometriyal kavitede yaklaşık 4 cm'lik sıvı varlığı, endometriyal örneklemede materyal olmaması, kitlenin sebat ediyor olması ve solid-kistik ayırımı yapılamaması nedenleriyle cerrahi tedavi planlanmıştır.

Vaka serileri tubaovaryan absesi olan postmenapozal kadınlarda malignensi oranının artmış olduğunu göstermiştir. Bir kliniğin 5 yıllık tubaovaryan abse olgu serisinde vakaların \%5,8 i postmenopozal olarak bildirilmiştir (9). Tubaovaryan absesi olan 93 hastayı içeren bir çalışmada, 76 premenapozal hastanın yalnızca birinde, 17 postmenopozal hastanın ise sekizinde (\%47) genital traktus ile ilişkili malignensi saptanmıştır (6). Bir kliniğin 10 yıllık postmenopozal TOA olgularının incelendiği çalışmada toplam 6 hasta saptanmış, bu hastaların 3 tanesinde konkomitan endometriyum kanseri, bir hastada ipsilateral ovaryan adenokarsinom ve bir hastada ise kolon adenokarsinom saptanmıştır (10). Hastaların parenteral tedaviye dirençlerinin araştırıldığı bir çalışmada ise TOA tanılı 40 yaş üzeri hastaların \%13'ünde malignensi saptanmıştır (11).

Olgumuzda da, postmenopozal hastamı tubaovaryan abse kliniği ile prezente olmuş, ancak cerrahi sonrası patoloji raporu malignensi ile uyumlu olarak bildirilmiştir. Bu nedenle postmenopozal tubaovaryan absesi olan hastalara malignensi riski ve cerrahi evreleme prosedürleri hakkında danışmanlık verilmelidir. Antibiyotik veya minimal invaziv drenaj prosedürleri yerine cerrahi tanı ve tedavi önerilmelidir. İntraoperatif frozen section analizi mutlaka yapılmalı, pelvis ve abdomen, metastatik hastalık açısından araştırılmalıdır.

Sonuç olarak; TOA, postmenapozal hastalarda oldukça nadir görülmekle birlikte, eşlik eden jinekolojik malignensi olabileceği göz önünde bulundurularak, tedavi planı bu yönde düzenlemelidir ve hastalar bu konuda bilgilendirilmelidir.

\section{Çıkar Çatışması}

Yazarlar herhangi bir çıkar çatışması bildirmemişlerdir.

\section{KAYNAKLAR}

1. Wiesenfeld HC, Sweet RL, Ness RB, Krohn MA, Amortegui AJ, Hillier $\mathrm{SL}$. Comparison of acute and subclinical pelvic inflammatory disease. Sex Transm Dis 2005;32:400-5.

2. Hsiao SM, Hsieh FJ, Lien YR. Tuboovarian abscesses in postmenopausal women. Taiwan J Obstet Gynecol 2006;45:234-8.

3. Sørbye IK, Jerve F, Staff AC. Reduction in Hospitalized women with pelvic inflammatory disease in Oslo over the past decade. Acta Obstet Gynecol Scand 2005;84:290-6.

4. Sonja A. Rasmussen. Sexually Transmitted Diseases Treatment Guidelines, Pelvic Inflamatory Disease June 5, 2015, page:78-81, Available from: URL: https://www.cdc.gov/std/tg2015/tg-2015 print.pdf

5. Protopapas AG, Diakomanolis ES, Milingos SD, Rodolakis AJ, Markaki SN, Vlachos GD et. al. Tubo-ovarian abscesses in postmenopausal women: gynecological malignancy until proven otherwise? Eur J Obstet Gynecol Reprod Biol. 2004 Jun 15;114:203-

6. Alcazar JL, Pascual MA, Marquez R, Ajossa S, Juez L, Graupera B et. al. Malignancy risk of sonographically benign appearing purely solid adnexal masses in asymptomatic postmenopausal women. Menopause. 2017;24: 613-6.

7. Kinkel K, Lu Y, Mehdizade A, Pelte MF, Hricak H .Indeterminate ovarian mass at US: incremental value of second imaging test for characterization--meta-analysis and Bayesian analysis. Radiology. 2005;236:85

8. The role of the obstetrician-gynecologist in the early detection of epithelial ovarian cancer. Committee Opinion No. 477. American College of Obstetricians and Gynecologists. Obstet Gynecol 2011; 117:742.

9. B Arıcı, A E Yumru, S Salman, A Bozyiğit, B Dinçgez. Kliniğimizde Opere Olan Tubaovarian Abse Olgularının Retrospektif Analizi. Yen Tıp Dergisi 2013;30:62-5

10. Kremer S, Kutcher R, Rosenblatt R, McGill F, Rozenblit A, Goldman M. Postmenopausal tubo-ovarian abscess: sonographic considerations and clinical significance. J Ultrasound Med. 1992;11:613-6.

11. Taichi Mizushima, Hiroshi Yoshida, Yuka Ohi, Masahiko Ishikawa and Fumiki Hirahara .Evaluating the risk factors for developing resistance to parenteral therapy for tubo-ovarian abscess: A casecontrol study, J. Obstet. Gynaecol. Res. 2013;39:1019-23 